\title{
AZF MICRO-DELETION IN AZOOSPERMIA AND SEVERE OLIGOSPERMIA: MOLECULAR \& HISTOPATHOLOGICAL STUDY IN DUHOK PROVINCE
}

\author{
Rana Adel Hanoon ${ }^{\mathrm{a}, *}$, Alaa Hani Raziq ${ }^{\mathrm{b}}$, Farida Fariq Nerwey ${ }^{\mathrm{c}}$ \\ ${ }^{a}$ Scientific Research Center, College of Science, University of Duhok, Kurdistan Region, Iraq - (rana.hanon@uod.ac) \\ ${ }^{\mathrm{b}}$ College of Medicine, University of Duhok, Kurdistan Region, Iraq \\ ${ }^{\mathrm{c}}$ College of Nursing, University of Duhok, Kurdistan Region, Iraq
}

\begin{abstract}
:
$\mathrm{Y}$ chromosome micro-deletion (YCM) is a set of genetic diseases caused by missing gene (s) in specific regions of the $\mathrm{Y}$ chromosome. Many individuals with YCM show no manifestations and lead normal life. On the other hand, YCM is known to exist in a significant number of infertile males. Forty adult patients suffering from severe oligospermia and azoospermia were involved in the present study. Seminal fluid analyses were performed, and a blood sample was obtained for hormonal analysis and DNA extraction. Follicle stimulating hormone (FSH) and luteinizing hormone (LH) profiles were measured and those who are azoospermic with normal FSH levels were subjected to testicular biopsy. The results revealed that 23 patients were azoospermic while 17 patients were severe oligospermic. It is also shown that ten azoospermic patients had normal serum gonadotrophin levels thus they were directed for testicular biopsy. Histopathological examination of testicular biopsy showed that four patients had obstructive azoospermia while the remaining six suffered from maturation arrest. DNA was extracted according to the standard proteinase K/phenol-chloroform method in the medical biotechnology laboratory/Scientific Research Center/University of Duhok. Multiplex PCR was performed for genes located in the azoospermia factor (AZF) regions (AZFa, AZFb, and AZFc) to detect any possible micro-deletions. Y chromosome micro-deletions were determined in 26 patients out of a total of forty patients. Microdeletions in the AZFc sub-region appeared in 16 out of 26 patients $(61.5 \%)$, and 10 (38.5\%) samples showed AZFb, however, AZFa micro-deletion was not detected in any of the patients. In conclusion, it has been found that $\mathrm{Y}$ chromosome micro-deletions in the AZF region can be a determining factor for male infertility and the consequential manifestations.
\end{abstract}

KEYWORDS: Azoospermia, oligospermia, Y chromosome microdeletions, Multiplex PCR, hormonal profile.

\section{INTRODUCTION}

Infertility is a significant health and reproductive issue that affects 10 to $15 \%$ of couples, of which approximately $50 \%$ of the cases are due to male factors (Foresta et al., 2001). Estimations pointed that infertility of the male is mainly due to azoospermia and it is prevalent in $10-15 \%$ of infertile men (Cocuzza et al., 2013). Several studies have elucidated diverse etiology for azoospermia but in many situations the main reason is still vague (Boettger-Tong, 2008).

Previous reports proposed an impaired spermatogenesis as a cause for male infertility which in turn resulted from mutations or deletions in specific genes which control that function (Mitra, 2008). In the male, sex determination is governed by an area located on the short arm of the $\mathrm{Y}$ chromosome known as sex-determining region (SRY) which is located on the short arm of the Y chromosome (Yp11), but the set genes involved in spermatogenesis are found on the nearby region of $\mathrm{Y}$ chromosome long arm (Yq11). This location of $\mathrm{Y}$ chromosome is known as the azoospermia factor (AZF) region and it consists of three sub-regions namely AZFa, AZFb and AZFc (Raicu et al., 2003). Deletions in each particular region occur with different frequency and can result in defective spermatogenesis with clinical outcomes ranging from complete absence of sperm in azoospermia or decreased sperm population in severe oligozoospermia Micro-deletion in the AZFc sub-region is almost associated with oligospermia while those occurring in the AZFa and AZFb sub-regions have been correlated with azoospermia. In general, deletions in the AZF region have been associated with altered sperm parameters and testicular histological characteristics (Thangaraj et al., 2003). Microdeletions in the AZF region are the most frequently encountered etiology for spermatogenesis defect. They may be diagnosed by molecular methods and are reported in 5-10\% of infertile males. The majority of studies assert that AZFc micro-deletions are the most frequent, followed by micro-deletions in the $\mathrm{AZFb}$ and AZFa sub-regions (Krausz et al., 2014). The frequency of the occurrence of micro-deletions can be very fluctuating due to the differences in many factors like $\mathrm{Y}$ chromosome background, the ethnicity of the selected patients, clinical criteria for patient selection, and methodological approachs (Naasse et al., 2015). The aim of the present study is to identify the types of microdeletions within the AZF region in azoospermic and oligospermic patients in Duhok province.

\section{MATERIALS AND METHODS}

Forty adult patients suffering from severe oligospermia and azoospermia from Duhok province/Kurdistan region/Iraq took part in the present study. Seminal fluid analyses (SFA) were performed according to the WHO guidelines (World Health Organization, 1999), using Weili color sperm analysis system ver. 6.3 (Beiing Weili New Century Science \& Technology Development Co. Ltd). According to the results of SFA, candidate individuals were divided into two groups; those with complete absence of sperms were assigned to azoospermia group while those with sperm count less than $5 \times 106$ sperm $/ \mathrm{ml}$ were considered severely oligospermic.

\footnotetext{
* Corresponding author

This is an open access under a CC BY-NC-SA 4.0 license (https://creativecommons.org/licenses/by-nc-sa/4.0/)
} 
The blood sample was divided into two parts; four ml was poured into EDTA tubes to extract DNA and the rest were used for hormonal analysis. Follicle stimulating hormone (FSH) and luteinizing hormone (LH) profiles were measured by immunofluorescence using Vidas (bioMérieux®, France) system and the results were analysed and interpreted by BMXSOFTWARE; serum FSH level ranging between 1.7$12 \mathrm{mIu} / \mathrm{ml}$ was considered normal and normal ranges for serum LH level was1.7-7 $\mathrm{mIu} / \mathrm{ml}$. Patients who are azoospermic with normal FSH and LH levels and normal testes size were subjected to testicular biopsy.

The molecular work started with DNA extraction from patient's leukocytes according to the standard proteinase $\mathrm{K}$ / phenol-chloroform protocol in the laboratory of medical biotechnology at the Scientific Research Center/University of Duhok (Grimberg et al., 1989), then primers for multiplex PCR assays were carefully selected according to the EAA (European Academy of Andrology)/EMQN (European Molecular Genetic Quality Network) guidelines (Simoni et al., 2004). The selected primers were assigned into two subsets each consisted of six primers (forward and reverse) specific for the three AZF loci (AZFa, AZFb, and AZFc) (Table 1, 2). Finally, STS primer of SRY (internal control) was included with each set of multiplex PCR to insure the accuracy of the procedure.

Table 1. Primers sequences \& products size of the mix A group

\begin{tabular}{|c|c|c|c|c|}
\hline \multicolumn{5}{|c|}{ Master Mix Primers-1 } \\
\hline STS & $\begin{array}{c}\text { Forward } \\
\text { primer }\end{array}$ & Reverse primer & $\begin{array}{c}A Z F \\
\text { interval }\end{array}$ & $\begin{array}{l}\text { Size of } \\
\text { products } \\
\text { (bP) }\end{array}$ \\
\hline SRY & $\begin{array}{l}\text { 5-GAA TAT } \\
\text { TCCGC TCT } \\
C C G \text { GA-3 }\end{array}$ & $\begin{array}{l}\text { 5-GCT GGT } \\
\text { GCT CCA TTC } \\
T T C A G-3\end{array}$ & & $499 \mathrm{bp}$ \\
\hline SY254 & $\begin{array}{l}\text { 5-GGG TGT } \\
T A C C A G \\
A A G G C A \\
A A-3\end{array}$ & $\begin{array}{l}\text { 5-GAA CCG TAT } \\
\text { CTA CCA AAG } \\
\text { CAG C-3 }\end{array}$ & $A Z F \mathrm{c}$ & $400 \mathrm{bp}$ \\
\hline SY84 & $\begin{array}{l}\text { 5-AGA AGG } \\
\text { GTC TGA } \\
A A G C A G \\
G T-3\end{array}$ & $\begin{array}{l}\text { 5-GCC TAC TAC } \\
C T G G A G G C T \\
T C-3\end{array}$ & $A Z F \mathrm{a}$ & $326 \mathrm{bp}$ \\
\hline SY127 & $\begin{array}{l}5-G G C T C A \\
C A A A C G \\
A A A A G A \\
A A-3\end{array}$ & $\begin{array}{l}\text { 5-CTG CAG } \\
\text { GCA GTA ATA } \\
A G G \text { GA-3 }\end{array}$ & $A Z F \mathrm{~b}$ & $274 \mathrm{bp}$ \\
\hline
\end{tabular}

Table 2. Primers sequences \& products size of the mix B group

\begin{tabular}{|c|c|c|c|c|}
\hline \multicolumn{5}{|c|}{ Master Mix Primers-2 } \\
\hline STS & Forward primer & Reverse primer & $\begin{array}{c}A Z F \\
\text { interval }\end{array}$ & $\begin{array}{l}\text { Size of } \\
\text { products } \\
\text { (bP) }\end{array}$ \\
\hline SRY & $\begin{array}{c}\text { 5-GAA TAT } \\
\text { TCCGC TCT } \\
C C G G A-3\end{array}$ & $\begin{array}{c}\text { 5-GCT GGT GCT } \\
\text { CCA TTC TTC } \\
A G-3\end{array}$ & & 499 bp \\
\hline SY86 & $\begin{array}{c}5^{\prime}- \\
\text { GTGACACACA } \\
\text { GACTATGCTT } \\
C\end{array}$ & $\begin{array}{c}5 \text { '- } \\
\text { ACACACAGAGG } \\
\text { GACAACCCT }\end{array}$ & $A Z F a$ & $320 \mathrm{bp}$ \\
\hline SY134 & $\begin{array}{c}\text { 5-GTC TGC } \\
C T C A C C A T A \\
A A C G-3\end{array}$ & $\begin{array}{c}\text { 5-ACC ACT GCC } \\
\text { AAA ACT TTC } \\
A A-3\end{array}$ & $A Z F b$ & 301 bp \\
\hline SY255 & $\begin{array}{c}\text { 5-GTT ACA } \\
\text { GGA TTC GGC } \\
\text { GTAT-3 }\end{array}$ & $\begin{array}{c}\text { 5-CTC GTC ATG } \\
\text { TGC AGC CAC- } \\
3\end{array}$ & $A Z F \mathrm{c}$ & 126 bp \\
\hline
\end{tabular}

Multiplex polymerase chain reaction (m-PCR) mixtures were prepared in two separate mixes namely, A and B. Each of the mix contained $12.5 \mu 1$ master mix $(0.4 \mathrm{mM}$ dNTPs mix; 4.5
$\mathrm{mM} \mathrm{MgCl2;} \mathrm{1U} \mathrm{Taq} \mathrm{DNA} \mathrm{polymerase;} \mathrm{1X} \mathrm{PCR} \mathrm{buffer)}$ (Promega ${ }^{\circledR}$, USA), $1 \mu$ l of each primer forward and reverse of each single individual gene (10 picomol/ml), and $2 \mu 1$ template DNA, then distilled water was added to attain a final volume of $25 \mu 1$.

Amplification conditions were set as follows: 4 minutes initial denaturation at $94^{\circ} \mathrm{C}$ followed by 40 cycles of 1 minute denaturation at $94^{\circ} \mathrm{C}, 45$ seconds annealing at $56^{\circ} \mathrm{C}$ and 4 minutes extension at $67^{\circ} \mathrm{C}$, followed by a final step of extension for 7 minutes at $67^{\circ} \mathrm{C}$. Afterwards, PCR products were electrophoresed on $2.5 \%$ agarose gel. PCR amplification bands were visualized using ethidium bromide gel staining for 30 minutes. Multiplex PCR conditions were adopted after several trials and as per previous work (Kyumars et al., 2013).

\section{RESULTS}

The results of the current study indicated that out of the 40 patients, 23 were azoospermic $(57.5 \%)$ while 17 patients had severe oligospermia $(42.5 \%)$. The results also revealed that 13 azoospermic patients out of the $23(56.5 \%)$ had elevated serum FSH and LH levels. While the remaining 10 patients $(43.5 \%)$ showed normal gonadotrophins serum profiles and thus they were subjected to testicular biopsy, which revealed that 4 out of 10 had normal spermatogenesis reflecting obstructive azoospermia (Figure 1) while the other 6 had maturation arrest (Figure 2).

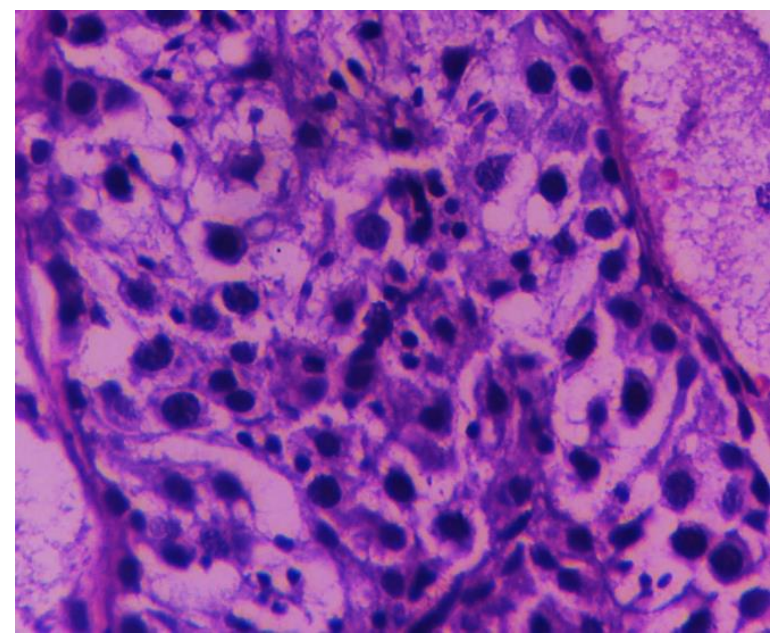

Figure 1. A testicular biopsy from a patient with obstructive azoospermia, note the presence of many spermatozoa in the seminiferous tubules

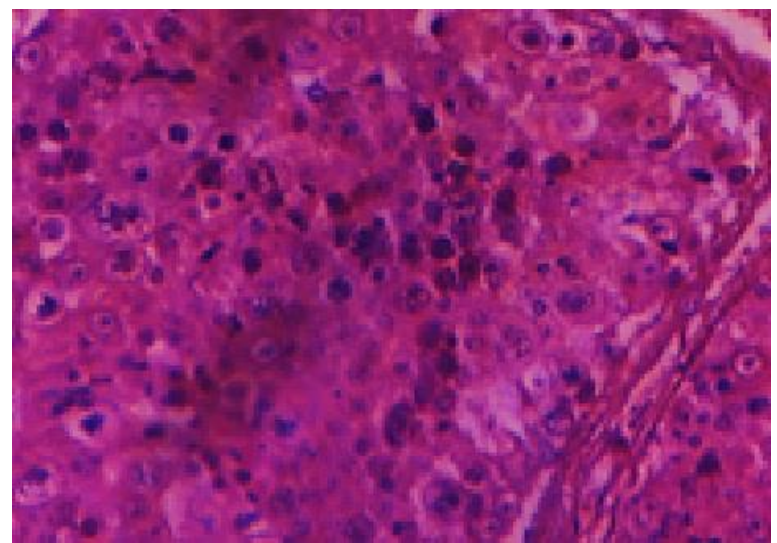

Figure 2. A testicular biopsy from a patient with azoospermia due to maturation arrest, note the presence of many spermatocytes with the absence of spermatids and spermatozoa in the seminiferous tubules. 
The results of the molecular study showed that $\mathrm{Y}$ chromosome micro-deletion was observed in $26(65 \%)$ patients out of a total of 40. Micro-deletions in the AZFc subregion appeared in 16 patients out of $26(61.5 \%)$, and 10 (38.5\%) samples showed AZFb micro-deletion, while AZFa micro-deletion was not found in any of the patients.

In the present work, mix A (consists of SRY14, SY254, SY84, and SY127 represented by 499 bp, 400 bp, 326 bp, and 274 bp, respectively.) was amplified by multiplex PCR to confirm the existence or the absence of the above mentioned mutations. Figure 3 shows the electrophoresis patterns of normal individuals holding the three bands of the AZF region.

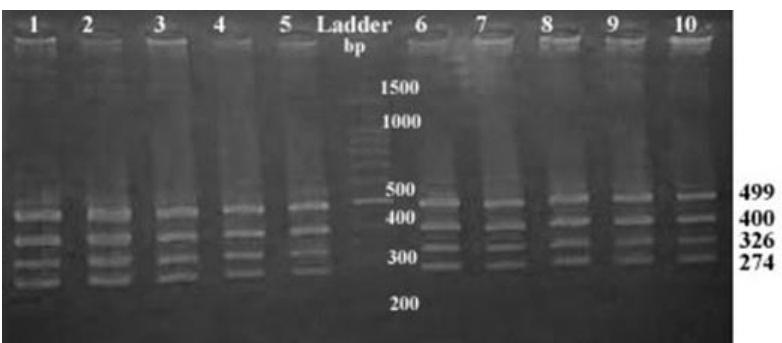

Figure 3. Elecrtophoretic profile of normal individuals having the three AZFa (SY84, 326bp), AZFb (SY127, 274bp), and AZFc (SY254, 400bp) regions plus the internal control SRY14 (499bp).

In the entire tested sample, the results revealed that AZFa (SY84) micro-deletion was not evident and thus a band of 326 bp appeared after being electrophoresed and stained while AZFb (SY127) and AZFc (SY254) have both been deleted and thus their relevant bands did not appear in the electrophorogram (Figure 4).

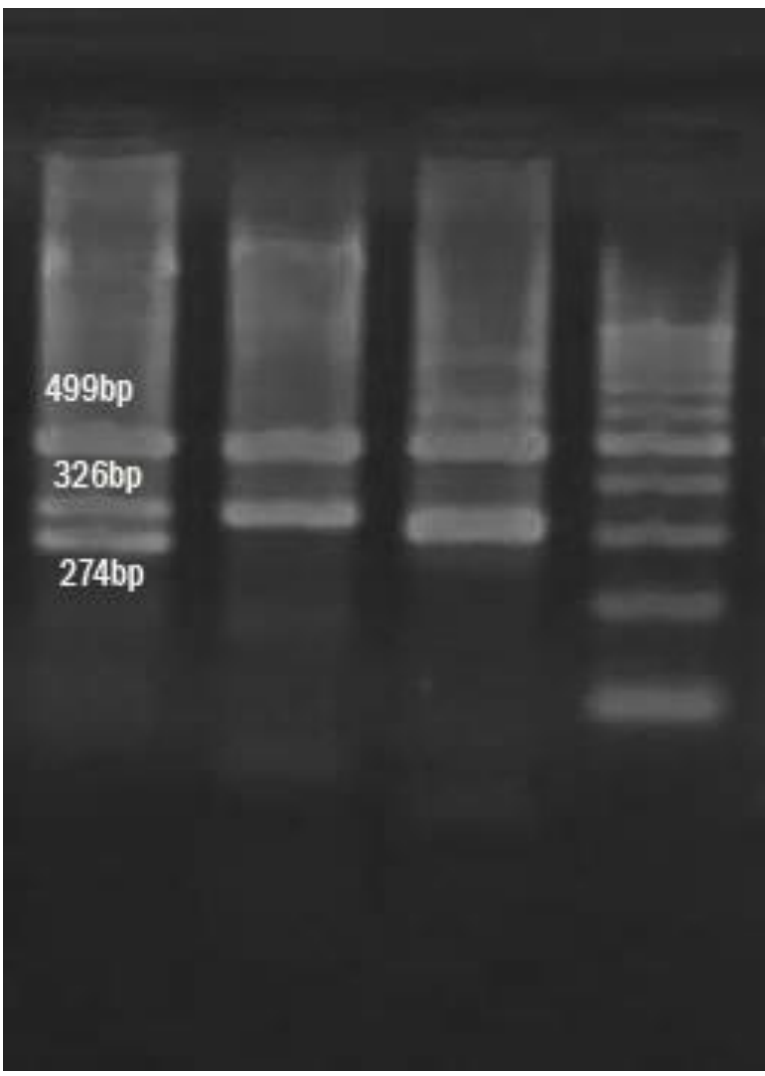

Figure 4. Electrophoresis patterns of individual patients. Lane 1 shows micro-deletion of the AZFc region. Lane 2 and 3 show micro-deletions in $\mathrm{AZFb}$ and AZFc. Lane 4 shows molecular weight marker $(100 \mathrm{pb})$
The results of multiplex PCR reaction concerning mix B (consist of SRY14, SY255, SY86, and SY134 represented by 499 bp, 126 bp, $320 \mathrm{bp}$, and $301 \mathrm{bp}$, respectively.) showed that normal electrophorogram contains four bands corresponding to the three $\mathrm{Y}$ chromosome regions $\mathrm{AZFa}, \mathrm{AZFb}$, and AZFc beside internal control represented as SRY14 (Figure 5).

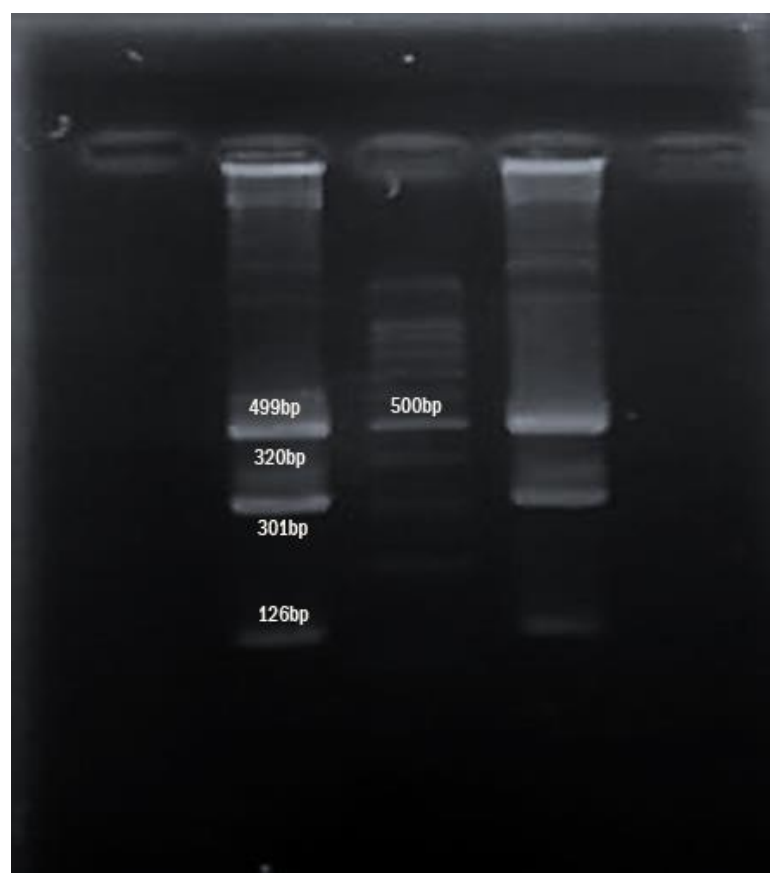

Figure 5. Elecrtophoretic profile of normal individuals having the three AZFa (SY86, 320bp), AZFb (SY134, 301bp), and AZFc (SY255,

126bp) regions plus the internal control SRY14 (499bp) in lane 1, Lane $\mathrm{M}$ contains molecular weight marker (100 bp). Lane 2 also shows normal individual profile.

A band of 320 bp has been observed indicating that AZFa (SY86) region was not deleted. On the other hand, AZFb (SY134) and AZFc (SY255) regions have both been deleted and therefore their relevant bands did not appear in the electrophoresis gel (Figure $6)$.

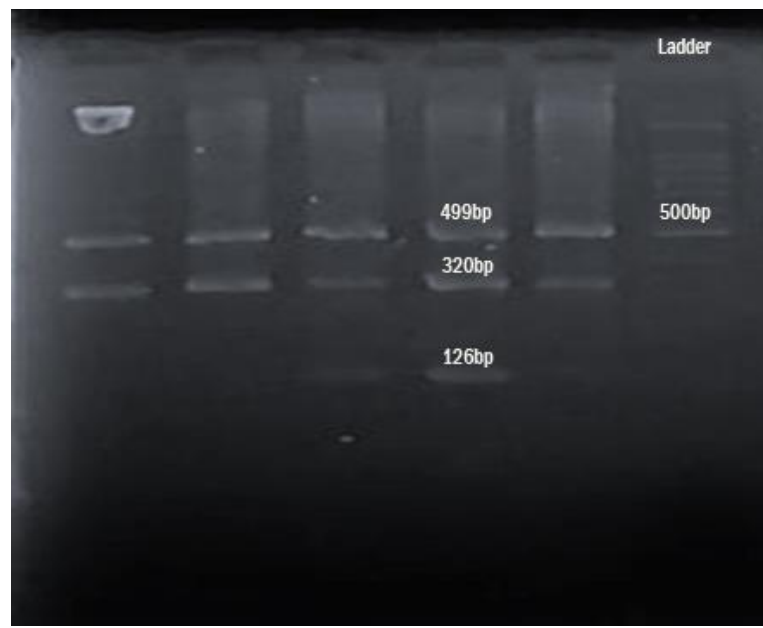

Figure 6. Electrophoresis patterns of individual patient. Lane 1, 2, 3, and 5 show micro-deletions of AZFc and AZFb. Lane 4 shows microdeletion in AZFb.

\section{DISCUSSION}

Testicular biopsy is particularly helpful in patients with azoospermia and normal gonadotrophins levels. Generally speaking, four patterns exist namely: germ cell aplasia, 
spermatocytic arrest, generalized fibrosis and normal apermatogenesis (Rosai, 2004). In this study, patients with generalised fibrosis and germ cell aplasia were excluded from testicular biopsy testing on the bases of clinical examination and hormonal profile study. Therefore, those subjected to testicular biopsy had either maturation arrest or normal spermatogenesis.

Deletions in the AZF region take place in $\mathrm{Y}$ chromosome and can cause serious impact in the genes responsible for spermatogenesis. These micro-deletions are attributed to intra-chromosomal re-arrangement among long homologous repetitive sequences (Repping et al., 2002) and ranked second to Klinefelter's syndrome when the etiologies for male infertility and spermatogenic defects are considered (Zaimy et al., 2013). The results of the present work reported much higher rate for $\mathrm{Y}$ chromosome micro-deletions in both azoospermic and oligospermic individuals as compared to that observed by others who stated that $1-55 \%$ of infertile men suffered from Y chromosome micro-deletions. Generally, most researchers have mentioned a rate of less than $10 \%$ (Poongothai et al., 2009). Consistent with previous reports, the results of the present study also revealed that micro-deletions in $\mathrm{AZFc}$ region of the $\mathrm{Y}$ chromosome prevailed when the three sub-regions were taken into consideration and thus it can be considered as one of the primary causes for spermatogenic defects (Moyet Al-Faisal et al., 2010; Yamada et al., 2010). The ratio of AZF microdeletion is still higher than in the ratio of the studies conducted in the near vicinity of Iraq. Y chromosome microdeletion rates of $24.2 \%$ and $50 \%$ were reported by Omrani et al., (2006) and Malekasgar et al., (2014), from northwest and south of Iran, respectively. The discrepancy in results may be explained in part by ethnicity differences, components of the sample size, population under study and lastly the application of specific STS markers. Six STS markers (two for each region) have been suggested by the EAA/EMQN best practice guideline to enable the accurate determination of all clinically relevant microdeletion (Malekasgar and Mombaini, 2008). In line with the results of current study, AZFc has been found to cause the majority of $\mathrm{Y}$ chromosome micro-deletions as it was detected in $70 \%$ of cases studied by Oates et al., (2002). Lower rates approaching 7\% have been observed in Turkey (Sargin et al., 2004) and Kuwait (Alkhalaf and Al-Shoumer, 2010), in comparison to the results of the present work. Frequencies of micro-deletions observed in different studies are inconsistent with each other and the cause-effect relationship among subdeletions and spermatogenesis is still controversial (Abilash et al., 2010). The geographical location and ethnic background might influence these deletions in the AZF regions; possibly in both the patterns of deletion and the phenotypic outcome. The change in the frequency of $\mathrm{Y}$ chromosome micro-deletion is also a subject of sample size and endocrine disorder or an undefined environmental influence (Page et al., 1999). Micro-deletions in $\mathrm{Y}$ chromosome can lead to progressive worsening of spermatogenesis and that as time passes oligospermic men can turn into azoospermic (Dada et al., 2004). The serious consequences of $\mathrm{Y}$ chromosome micro-deletions and the harmful phenotypic manifestations necessitate an accurate determination of the transcriptional activities of various genes on the $\mathrm{Y}$ chromosome primarily those found in the AZF region and are mainly associated with male infertility. In conclusion our results emphasize the critical role of $\mathrm{Y}$ chromosome micro-deletions in the pathology of male infertility.

\section{REFERENCES}

Abilash, V. G.; Saraswathy, R.; Marimuthu, K. M. (2010). The frequency of $\mathrm{Y}$ chromosome microdeletions in infertile men from Chennai, a South East Indian population and the effect of smoking, drinking alcohol and chemical exposure on their frequencies. Int. J. Genet. Mol. Biol. 2: 147-157.

Alkhalaf, M. and Al-Shoumer, K. (2010). Cytogenetics abnormalities and azoospermia factor (AZF) microdeletions in infertile men from Kuwait. J. Mol. Genet. Med. 4: 232-234.

Boettger-Tong, H. (2008). Genes Causing Azoospermia and Oligozoospermia. Glob. Libr. Women's Med.

Cocuzza, M.; Alvarenga, C.; and Pagani, R. (2013). The epidemiology and etiology of azoospermia. Clinics. 68:15-26.

Dada, R.; Gupta, N. P.; and Kucheria, K. (2004). Yq microdeletions azoospermia factor candidate genes and spermatogenic arrest. J. Biomol. Tech. 15: 176183.

Foresta, C.; Moro, E.; and Ferlin, A. (2001). Y chromosome microdeletions and alterations of spermatogenesis. Endocr. Rev. 22(2): 226-239.

Grimberg, J.; Nawoschik, S.; Belluscio, L. et al. (1989). A simple and efficient non organic procedure for the isolation of genomic DNA from blood. Nucleic Acids Res. 17:83-90.

Krausz, C.; Hoefsloot, L.; Simoni, M.; Tüttelmann, F. (2014). European Academy of Andrology; European Molecular Genetics Quality Network. EAA/EMQN best practice guidelines for molecular diagnosis of Y-chromosomal microdeletions: stateof-the-art 2013. Andrology. 2(1): 5-19.

Krausz, C.; Hoefsloot, L.; Simoni, M.; Tüttelmann, F.; (2014). European Academy of Andrology; European Molecular Genetics Quality Network. EAA/EMQN best practice guidelines for molecular diagnosis of Y-chromosomal microdeletions: stateof-the-art. Andrology. 2(1): 5-19.

Kyumars, S.; Yadegar, L.; Massoud Houshmand, M.; Mirfakhraie, M.; and Mohammadi, E. (2013). Y chromosome Microdeletions in Infertile Men with Severe Oligozoospermia. J. Basic. Appl. Sci. Res. 3(2):786-791

Malekasgar, A.M.; and Mombaini, H. (2008). Screening of' $Y^{\prime}$ chromosome microdeletions in Iranian infertile males. Journal of human reproductive sciences.1(1):2.

Mitra, A.; Dada, R.; Kumar, R.; Gupta, N. P.; Kucheria, K.; and Gupta, S. K. (2008). Screening for Y-chromosome microdeletions in infertile Indian males: utility of simplified multiplex PCR. Indian J. Med. Res. 127(2): 124-132.

Moyet Al-Faisal, A. H.; Alnajar, A. F.; and Ghareeb, A. A. M. (2010). AZF, SRY microdeletions and hormonal disturbances among azoospermic Iraqi men. IJPS. 6(2): 92-97.

Naasse, Y.; Charoute, H.; El Houate, B.; Elbekkay, C.; Razoki, L.; Malki, A.; Barakat, A.; and Rouba, H. (2015). Chromosomal abnormalities and $\mathrm{Y}$ chromosome microdeletions in infertile men from Morocco. BMC Urology. 15 (95):1-6.

Oates, R.D.; Silber, S.; Brown, L. G.; and Page, D. C. (2002). Clinical characterization of 42 oligospermic or azoospermic men with microdeletion of the AZFc region of the Y chromosome, and of 18 children conceived via ICSI. Hum. Report. 17(11): 2813-2824.

Omrani, M. D.; Samadzadae, S.; Bagheri, M.; and Attar, K. (2006). Y chromosome microdeletions in idiopathic infertile men from west Azarbaijan. Urol. J. 3(1): 38-43.

Page, D.C.; Silber, S.; and Brown, L. G. (1999). Men with infertility caused by AZFc deletion can produce sons by intracytoplasmic sperm injection, but are likely to transmit the deletion and infertility. Hum. Repord. 14 (7): 1722-1726.

Poongothai, J.; Gopenath, T. S.; and Manonayaki, S. (2009). Genetics of human male infertility. Singapore Med. J. 50(4): 336-347

Raicu, F.; Popa, L.; Apostol, P.; Cimpomeriu, D.; Dan, L.; Ilinca, E. et al. (2003). Screening for microdeletions in human $\mathrm{Y}$ chromosome--AZF candidate genes and male infertility. J. Cell. Mol. Med. 7(1): 43-48.

Repping, S.; Skaletsky, H.; Lange, J.; Silber, S.; Van Der Veen, F.; Oates, R. D. et al. (2002). Recombination between palindromes P5 and $\mathrm{P} 1$ on the human $\mathrm{Y}$ chromosome causes massive deletions and spermatogenic failure. Am. J. Hum. Genet. 71(4): 906922.

Rosai J. R. (2004). Ackerman's surgical pathology. $9^{\text {th }}$ ed. Vol 1. Edinburgh: Mosby

Sargin, C.F.; Berker-karauzum, S.; Manguoglu, E.; Erdogru, T.; Karaveli, S.; Gulkesen, K. H. et al. (2004). AZF microdeletions on the 
Y chromosome of infertile men from Turkey. Ann. Genet. 47: 61-68.

Simoni, M.; Bakker, E.; and Krausz, C. (2004). EAA/EMQN best practice guidelines for molecular diagnosis of $\mathrm{Y}$ chromosomal microdeletions. State of the art 2004. Int. J. Androl. 27: 240-249.

Thangaraj, K.; Gupta, N. J.; Pavani, K.; Reddy, A. G.; Subramainan, S.; Rani, D. S. et al. (2003). Y chromosome deletions in azoospermic men in India. J. Androl. 24(4): 588-597.

World Health Organization. (1999). WHO Laboratory Manual for the Examination of Human Semen and Sperm-cervical Mucus Interaction, 4th ed. Cambridge: Cambridge University Press. 128 p.

Yamada, K.; Fujita, K.; Quan, J.; Sekine, M.; Kashima, K.; Yahata, T. et al. (2010). Increased apoptosis of germ cells in patients with AZFc deletions. J. Assist. Reprod. Genet. 27(6): 293-297.

Zaimy, M. A.; Kalantar, S. M.; Sheikhha, M. H.; Jahaninejad, T.; Pashaiefar, H.; Ghasemzadeh, J. et al. (2013). The frequency of $\mathrm{Yq}$ microdeletion in azoospermic and oligospermic Iranian infertile men. Iran J. Reprod. Med. 11(6): 453-458. 